University of Nebraska - Lincoln

DigitalCommons@University of Nebraska - Lincoln

Papers in the Earth and Atmospheric Sciences

Earth and Atmospheric Sciences, Department

$11-2009$

\title{
Coupled collaborative in-class activities and individual follow-up homework promote interactive engagement and improve student learning outcomes in a college-level Environmental Geology course
}

Leilani Arthurs

University of Nebraska-Lincoln, larthurs2@unl.edu

Alexis Templeton

University of Colorado at Boulder, alexis.templeton@colorado.edu

Follow this and additional works at: https://digitalcommons.unl.edu/geosciencefacpub

Part of the Earth Sciences Commons

Arthurs, Leilani and Templeton, Alexis, "Coupled collaborative in-class activities and individual follow-up homework promote interactive engagement and improve student learning outcomes in a college-level Environmental Geology course" (2009). Papers in the Earth and Atmospheric Sciences. 307.

https://digitalcommons.unl.edu/geosciencefacpub/307

This Article is brought to you for free and open access by the Earth and Atmospheric Sciences, Department of at DigitalCommons@University of Nebraska - Lincoln. It has been accepted for inclusion in Papers in the Earth and Atmospheric Sciences by an authorized administrator of DigitalCommons@University of Nebraska - Lincoln. 


\title{
Coupled collaborative in-class activities and individual follow-up homework promote interactive engagement and improve student learning outcomes in a college-level Environmental Geology course
}

\author{
Leilani Arthurs ${ }^{1,2}$, Alexis Templeton ${ }^{1,3}$
}

\begin{abstract}
Interactive engagement pedagogies that emerge from a constructivist model of teaching and learning are often a challenge to implement in larger classes for a number of reasons including the physical layout of the classroom (e.g. fixed chairs in an amphitheater-style room), the logistics of organizing a large number of students into small peerlearning groups, the ability of a single instructor to personally interact with each of many small groups, and the design of small group activities that are engaging and facilitate student learning. For a large introductory-level Environmental Geology college course, 5 coupled collaborative class-long in-class activities and individual follow-up homework were designed and implemented around key topics and specific learning goals. The goals behind designing and implementing these coupled in-class activities and homework were to (1) improve student attitudes towards science and learning science and (2) improve their content knowledge and conceptual understanding. To evaluate the extent to which these goals were achieved, 5 forms of assessment were used: a pre-instruction entrance questionnaire, pre- and post-instruction attitudinal surveys, pre- and post-instruction course tests, a post-instruction exit questionnaire, and post -instruction exit interviews. The findings from these forms of assessment suggest that the coupled in-class activities and individual follow-up homework improved targeted student learning outcomes.
\end{abstract}

\section{INTRODUCTION}

In creating a new lecture-based Environmental Geology course for primarily non-science majors at a large state university, we (a) grounded the approach to teaching and learning in the constructivist model of education and $(b)$ used "backward design" (Wiggins and McTighe, 2005) to first identify explicit learning goals and then use them to design the new course. More specifically, a large component of the course involved the development and implementation of coupled collaborative class-long inclass activities and individual follow-up homework.

An alternative to the traditional lecture course that conforms to the tranmissionist model of education is a learner-centered lecture course that is aligned with the constructivist model (Bransford et al., 2000). In traditional large lecture courses, the instructor and students operate under an agreement of complicity, where the instructor talks at the students and the students passively listen and try to absorb the information. This arrangement typically fosters passive learning by failing to fully engage the students in their own education. Only teacher-proof students (i.e. self-motivated and independent learners) will obtain the best learning outcomes under these conditions, as they would in almost any educational environment. Independent and self-motivated learners, however, represent only a small fraction of all students (Redish, 2003).

In contrast to the lecture-based transmissionist model, the constructivist model is focused on learner-centered teaching and active learning. Learner-centered teaching is largely concerned with recognizing and using students' existing knowledge, preconceptions, skills, and attitudes to facilitate new learning (Bransford et al., 2000). Furthermore, a learner-centered environment aids in the transition from dependence on the lecturer to intellectual

\footnotetext{
${ }^{1}$ Department of Geological Sciences, University of Colorado at Boulder, Campus Box 399, 2200 Colorado Avenue, Boulder, CO 80309-0399;

2Leilani.Arthurs@Colorado.EDU

3Alexis.Templeton@Colorado.EDU
}

autonomy (Kloss, 1994). Active learning is "a process in which students are actively engaged in learning" (Handelsman et al., 2007). The active engagement of students in their own learning may be promoted by including group problem-solving activities (i.e. cooperative learning) and by having students explore questions and answers to scientific phenomena (i.e. inquiry-based learning). The common feature among active learning methods "is that all students in a classroom need to do something [such as] quietly thinking, discussing an idea in a group, conducting an experiment, or writing a question or idea ... so that they are constructing knowledge" (Handelsman et al., 2007).

Science education research shows that "lecturing alone is a relatively ineffective way of teaching," and that learning (in terms of retention) from lectures is poor (Handelsman et al., 2007; Hake, 1997). Researchers have shown that students need not be teacher-proof in order to be successful; they have shown that students can be successful learners when they are actively learning (Umbach and Wawrzynski, 2005; Michael, 2006), which may include interacting with faculty (Gillespie, 2005), collaborating with peers (Crouch and Mazur, 2001), receiving regular feedback (Fink, 2003), and transferring the use of new knowledge in different contexts (Mayer, 2003). A key element of active learning is shifting the learning focus from only the acquisition of knowledge to what can be done with that knowledge (Sagendorf et al., 2009). Collaborative group learning appears in the literature as many different forms, and all studies suggest that collaborative learning improves student learning outcomes. For example, cooperative group learning has been demonstrated to have positive effects on problem solving (Heller et al., 1992; Fagen et al., 2002; Beichner and Saul, 2003). "Interactive engagement" (IE) is a phrase coined to describe a level of student participation in learning that can be hands on and is always minds on.

In creating a new Environmental Geology course that was primarily lecture based, we wanted to incorporate IE 
at a collaborative level and an individual level. Activities intended to better engage students in geoscience courses have been documented in the literature (e.g. Farver and Brabander, 2001; Lev, 2004; Liu et al., 2004; Robinson, 2001; Soja and Huerta, 2001; and Yuretich et al., 2001), and form a reference point for the creation and implementation of new activities.

In light of what education research says about IE and how it fits into a constructivist paradigm of education, we experimented with several different kinds of strategies to create "minds on" and "hands on" learning experiences for the students of this course. A brief description of all these strategies is provided in the Pedagogical $\&$ Course Context section below; however, an in depth discussion of their design, implementation, and possible impact on student learning is beyond the scope of this paper. Our most concerted efforts in creating engaging student learning experiences resulted in the replacement of 5 lecture periods with 5 class-long collaborative in-class activities, which were then followed up with homework that students completed individually. These coupled collaborative in-class activities and individual follow-up homework assignments are the focus of this paper. Our reasons for writing this paper include a desire to share these coupled activities with readers and to provide an assessment of how they worked to achieve our student learning outcomes in the context of this introductory college-level Environmental Geology course.

Although the instructor produced a 7-page document that outlines specific learning goals for students to work towards during the semester, we had in the forefront of our minds 2 overarching student learning outcomes that governed our desire to design and implement the coupled collaborative in-class activities and individual follow-up homework assignments. (1) Improve student attitudes towards science and learning science (e.g. develop students' sense of confidence in making sense of the effects of human activities on geological and environmental process), and (2) improve students' content knowledge and conceptual understanding of rock, water, and mineral resource cycles.

\section{METHODS}

\section{Institutional Review Board (IRB) Protocols Approval}

We received approval for the administration of preand post-instruction surveys in $\mathrm{CU}$ courses as well as student interviews from the University of Colorado IRB (protocol 0603.08).

\section{Physical Context \& Class Demographics}

This Environmental Geology course was taught during the Fall 2007 semester at a large research university in the central U.S., the University of Colorado at Boulder. The classroom in which the course was taught was approximately $7.62 \mathrm{~m}$ long and $13.41 \mathrm{~m}$ wide. Two large chalk boards and a retractable projector screen were located at the front of the classroom. The room was equipped with a hanging projector and wireless internet. Individual movable chairs with attached desk surfaces were aligned in parallel rows for lecture days and were stacked up against the walls during days where lecture was replaced with a class-long collaborative in-class activity.

The course was supported by an instructor (Templeton), a graduate student grader, a graduate student teaching assistant, and a Science Teaching Fellow (Arthurs). Only the instructor and grader were responsible for grading students' course work. The Science Teaching Fellow was a non-instructional faculty member. As such, she mainly provided behind-the-scenes support, unobtrusively recorded class observations and provided feedback to the instructor, and assisted the instructor and teaching assistant in facilitating most inclass activities. The class was comprised of 52 students. The class make-up of the students registered in the course at the end of the semester included 31 males and 21 females; 24 freshmen, 14 sophomores, 10 juniors, and 4 seniors; and $65 \%$ non-science-technology-engineeringmathematics (non-STEM) majors, 19\% STEM majors, and $35 \%$ undeclared or open option students.

\section{Pedagogical \& Course Context}

Each class meeting was 50 minutes long. The class convened 3 times each week over a 15-week semester, for a total of 43 class meetings and 37.5 contact hours. This was a lecture-based course and was neither associated with a lab nor a recitation section. The course was divided into six modules: (1) an introduction to physical geology, (2) basic hydrology, (3) mineral resources, (4) waste management, (5) water quality, and (6) conventional energy resources. Each module was developed with specific learning goals in mind, and a topic-specific coupled collaborative in-class activity and individual follow-up homework was developed and incorporated into the first 5 modules.

In this paper, we focus only on the coupled collaborative in-class activities and follow-up individual homework because they constituted the majority of IE time. It is, however, important to place these coupled activities in the larger context of the course by providing only a very brief description of the other strategies used to engage students during class time and outside of class at a collaborative level and an individual level. During class, students answered a total of 38 clicker questions either independently or after a brief time of consulting with a peer, collaboratively completed 1 short in-class group worksheet about student opinions regarding waste disposal, independently drew 1 concept sketch describing the water cycle, and participated in 2 short individualbased in-class activities that dealt with mineral crystal growth and mining. In addition to the homework, one additional out-of-class strategy used to engage students at an individual level was having them write 2 "Environmental Geology in the News" reports. In terms of the weight assigned to these various IE components of the course with respect to students' overall course grades, the breakdown is as follows: class-long in-class activities $10 \%$; homework (includes homework coupled with inclass activities and Environmental Geology in the News reports) 35\%; clicker questions 5\%; mid-term exam 20\%; and final exam $30 \%$. The waste disposal worksheet, concept sketch, and 2 short in-class activities did not factor 
into the calculation of the overall course grade.

\section{DESIGN}

\section{Universal Aspects of Design}

Development of the coupled in-class activities and follow-up homework encompassed several design objectives. Viewed as a set, each activity was designed with a different format in order to engage students in a variety of ways. Viewed chronologically, each subsequent coupled activity and homework was designed to demand greater degrees of intellectual rigor from the students. For example, the first coupled activity was fashioned as a fun low-key game to develop greater familiarity with the rock cycle; whereas the final capstone activity required simulation of an international working group charged with mitigating the real-life mass poisoning of the Bangladeshi people. The activities were intended to have an element of "desirable difficulty" (Bjork, 1994) that advanced students' acquisition of scientific knowledge, development of geology-based skills, and confidence and competence in applying information and skills to evaluate environmental issues that they might encounter in their day-to-day lives (e.g. through the news and/or through personal experiences).

The general character of the in-class activities lies somewhere between class-long strongly guided POGIL (process oriented guided inquiry learning) exercises (e.g. Moog and Farrell, 2006) and pre-lecture invention activities as used by Schwartz (2008). One element common to our in-class activities, POGIL exercises, and invention activities is that they require the students to work together in small groups to tackle questions and solve a variety of problems

The universal design objectives behind each collaborative in-class activity were that they:

(1) be tied to concepts and issues that students could connect to either on a personal level or as a relevant current environmental issue, locally or internationally; (2) required sustained student participation and engagement, and were doable in 50 minutes; (3) were collaborative in nature, and were doable in groups of 3-4; (4) encouraged and developed within the students a frame of mind that was fun, curious, inventive, creative, analytical, and/or organic; (5) required students to assimilate and apply topic-specific concepts and principles; and (6) prepared students to do the homework.

The universal design objectives behind each individual follow-up homework were that they: (1) required students to use the information and/or skills that they developed during the in-class activity to go more indepth into the topic introduced in the in-class activity and (2) addressed higher-level learning goals articulated by the instructor (also available on the Science Education Initiative (SEI) archive site at http://www.sei.ubc.ca/ materials $/$ sections.do?section $=$ overView \& courseId $=215$ \&departId=14).

\section{Topic-Specific Goals of Design}

Rock Cycle: The activity was adapted from a paperand-pencil homework assignment (Mayhew and Bair, 2007). This activity was designed as a game, with the intention of setting a relaxed tone and encouraging curiosity. The primary learning goal of the in-class activity was for students to predict what rock types form under different geological conditions. The primary objective of the follow-up homework was for the students to create their own conceptual diagrams of the full rock cycle by integrating all of their observations from the game.

Subsurface Water: There were 4 learning goals embedded into this in-class activity. Students were provided opportunities to (1) develop and use map reading and interpretation skills; (2) develop and use translation skills to extrapolate, visualize, and model 3-D structures after examination of a 2-D map; (3) identify subsurface rock units that could hold and transmit water; and (4) distinguish confined and unconfined aquifers. The homework then provided a framework for each student to evaluate their maps and models to define the connections between subsurface hard rock geology and the distribution, movement, and availability of groundwater resources.

Colorado "Uranium Boom": The overarching objective of this in-class activity was for students to critically evaluate public information regarding a proposal to implement new uranium mining technologies in Colorado. The homework then asked the students to use all of the information gleaned from the interview, their group discussion, and instructor-provided responses to groups' questions, to individually assess the environmental benefits and threats associated with in-situ uranium mining.

Water Quality and Drinking Water Standards: The purpose of this activity was two-fold: (1) Challenge students' perceptions of water quality and their knowledge of worrisome contaminants that might be present in their drinking water. (2) Provide an opportunity for students to actively learn about the U.S. Environmental Protection Agency's current maximum contaminant levels and treatment technologies for contaminants of interest to the students. This was the only in-class activity that was designed to be completed by the group during the class period, and was not coupled with an individual follow-up homework. Instead, the in-class activity required a consensus opinion retarding what potential contaminant was most worrisome in their drinking water and why.

Arsenic Poisoning in Bangladesh: This final in-class activity was a course capstone exercise that provided students the opportunity to integrate and apply the information and critical thinking skills that they had acquired and developed throughout the semester to evaluate the possible causes and solutions to a pressing epidemiological problem. The homework then asked each student to advocate a course of action that could help minimize exposure to arsenic contaminated groundwater.

\section{IMPLEMENTATION \\ Universal Aspects of Implementation}

At approximately the end of every other week, on a Friday, the lecture period was replaced with a collaborative class-long in-class activity. Prior to the day of in-class activity, the instructor randomly assigned 
students to small groups of 3-4. Membership of the small groups was shuffled for each in-class activity to allow students to meet and work with more of their peers. As students entered the classroom on the day of an in-class activity, they picked up a copy of the in-class activity's worksheet. These class days began with the instructor providing brief introductory remarks about the activity and posting the small group assignments on the overhead projector screen. The class of 52 students then divided itself into small groups of 3-4 students. It took the students $<2$ minutes to assemble into their small groups for all but the very first in-class activity (which took them closer to 4 minutes to assemble most likely because of the unfamiliarity with this practice). Depending on the activity, the students then rearranged their chairs into small circles and/or stacked the chairs against the walls of the classroom to provide more floor space.

As students worked together, the instructor, teaching assistant, and teaching fellow circulated around the room to stimulate students to discuss issues and ideas with each other, answer questions posed by each group, encourage a collaborative learning atmosphere to minimize individual competition that can sabotage collaborative learning efforts (Seymour and Hewitt, 1997), and facilitate discussion using the Socratic method. As the student groups completed each in-class activity, each student recorded the results of their collaborative efforts on their individual worksheet. These worksheets were neither collected nor graded; students kept them to complete their individual homework. When groups finished their collaborative in-class activity, they picked up the homework assignment and left the classroom prepared to complete it within the next week.

Because homework assignments could not be completed without the experiences and practice made possible through each in-class activity, students who did not attend class when there was in-class activity had to complete the activity during the instructor's office hours. All of the students doing the make-up worked together, typically in a group that totaled $\sim 3-5$ students.

\section{Topic-Specific Aspects of Implementation}

All 5 coupled activities contained the universal aspects of implementation described above; however, each one also had other aspects of implementation that were unique to it. In this section we describe the topic-specific aspects of each in-class activity.

Rock Cycle: This activity was played like a game, and small groups were asked to follow a rock as it was subjected to a sequence of 15 random geological processes. The activity was structured around five different rockrelated stations (which were located in separate and distinct areas in the classroom): magma, igneous rock, metamorphic rock, sediments, and sedimentary rocks. Each station displayed type-appropriate rock samples and housed a deck of cards made specifically for that particular station. Each card described a scenario of a geological process that the particular rock type might be subjected to (e.g., "You are deposited and buried by 10 kilometers of sediments."). In addition to the stations, 8.5" $x 11$ " images of the different geological processes (e.g., erosion, cementation, metamorphism, and burial) were taped on walls around the room and a figure of the pressure-temperature stability field for different rock types was projected onto a large screen at the front of the classroom. These were visual aids that student could refer to during the activity.

Each small group was asked to begin the activity at a randomly assigned station. One person in the group then selected a card on the group's behalf. After reading the scenario on the card out loud, the group made a collective decision about the kind of rock type they'd be transformed into given the geological process described on the selected card. After deciding on the new rock type, the group moved to the next appropriate station and again selected a new game card. Each group repeated this cycle for 14 iterations, and they recorded each geological process they were subjected to and rock type that they were transformed into as a result (see Supplemental Figure 1 on SEI archive site).

After the in-class exercise, each student completed a homework in which they first charted the progress of their group's game. Next, the students were asked to identify all of the pathways by which one rock type can be transformed into another, using their game experiences and lecture notes. This thought exercise then provided a framework for each student to produce a rock cycle diagram from first principles. These diagrams were significantly more annotated and comprehensive than any similar diagram to be found in a textbook.

Subsurface Water: At the start of this activity, each group picked up a ziplock bag containing a simplified geologic map of the Denver Basin, 4 canisters of different colored Play-Doh (which matched the colors of the 4 rock types illustrated on the geologic map), and a disposable plastic knife. With minimal guidance, the groups were asked to play with the Play-Doh and discover a way to create a 3-D Play-Doh model of the Denver Basin illustrated on the 2-D map. This process involved experimenting with different ways to layer, bend, and cut the Play-Doh (see Supplemental Figure 1 on SEI archive site). Students performed several iterations by trial and error. After a group created a 3-D model of some kind, the activity facilitators encouraged the group to assess the relationship of the rock layers in the cross-sectional slice.

Next, each group analyzed information about the individual rock types illustrated in the map and discussed questions that addressed key concepts related to the different rock types in the basin. In particular, the groups were asked to identify the rock types that could or could not serve as an aquifer and whether these aquifers would be confined or unconfined. They were also asked how water could get in and out of these aquifers and where it would be best to place a well to extract water from the aquifers.

In the homework, the students recreated their geological cross-sections and individually labeled the aquifers and aquitards. With this framework, the students were then asked to assess how the properties of each aquifer would vary (i.e. in terms of water storage capacity and ability to transmit water) using porosity and hydraulic conductivity data for each rock unit. In the final 
part of the homework, students were asked to integrate the in-class activity with lecture material to assess the anthropogenic effects of subsurface water extraction on the sustainability of groundwater resources.

Colorado "Uranium Boom": Students listened to an 11 minute National Public Radio interview produced by KCFR-Denver for the "Colorado Matters" series. During the interview, KFCR host, Ryan Warner, posed questions to a representative from Powertech, USA, an international corporation that putting forward a proposal to use in-situ leaching technologies to extract uranium in Centennial, CO. This interview informed students about a debate over using new uranium mining technologies and their potential environmental impacts. Students were asked to record notes and questions that came to mind as they listened to the interview. After listening to the interview, students assembled into their small groups. Each group then discussed the content of the interview, figured out what they collectively understood about this complex topic, determined what additional information they thought they needed to more fully understand the new technology and possible environmental impacts, and recorded the specific questions their group generated. During these small group discussions, the activity facilitators circulated around the room, primed with answers to several pre-anticipated questions (e.g., What is in-situ leaching? What kind of feasibility studies has Powertech conducted?). At the end of class, each group submitted a long list of questions to the instructor. Within 2 days, the instructor then provided individual responses to each group's questions via email. The groups' questions and instructor responses formed an information base that the students used to complete their homework.

The homework asked students to evaluate the mining plans proposed in the interview and articulate what information was most important to them in understanding the issues involved. Each student was also asked to explicitly identify potential pathways for groundwater contamination by reviewing schematic diagrams of the injection and extraction wells. To conclude, they were asked to recommend a course of resource extraction, environmental monitoring, and community involvement that might be acceptable to both stakeholders of Powertech, USA, and the residents of Centennial, CO. Examples of the student-generated questions and responses can be found at the Science Education Initiative (SEI) archive site.

Water Quality and Drinking Water Standards: For this activity, students were asked in advance to bring and share their lap tops. On the day of the in-class activity, the instructor began the class meeting with a demonstration that qualitatively estimated the nitrate concentrations of 3 different water samples obtained at different locations along Boulder Creek using a colorimetric Hach field-test kit. This demonstration included an explanation for why nitrate might be considered a contaminant (i.e., blue-baby syndrome), a definition of the maximum contaminant level (MCL) for nitrate in drinking water, and a discussion of the actual quantitative measurements of nitrate concentration in local waters sampled before and after entry into the Boulder, $\mathrm{CO}$, municipal water treatment facility.

Following the demonstration, students assembled into their small groups and were given worksheets to complete during the in-class activity. Groups were asked to generate a list of up to 8 potential contaminants in their water supply that worry them the most. They were then asked to select what they considered the top 4 most worrisome contaminants from their list. Students then used their laptops and wireless internet to access the EPA's website to learn more about their top 4 contaminants. On their worksheets, students recorded each contaminant's MCL, health effects, methods of release into environment, and the EPA approved treatment methods. After learning more about their selected contaminants, each group had to decide which one of the 4 contaminants they believed posed the greatest threat and explain the basis of their decision. All students completed their worksheets during the class period and there was no follow-up homework for this activity.

Arsenic Poisoning in Bangladesh: The lecture period prior to this in-class activity was dedicated to presenting arsenic as a common contaminant in groundwater, describing the health effects associated with chronic and acute arsenic poisoning, and recounting the disagreement over the acceptable levels of dissolved arsenic recommended by the United States and the World Health Organization. During this lecture, the instructor also described the general geological setting of Bangladesh, and she addressed results of epidemiological studies that indicated there is a mass poisoning of the Bangladeshi population due to consumption of drinking water contaminated with arsenic.

Prior to the day of the in-class activity, specialized packets of information that were compiled from websites maintained by the British Geological Survey, Richard Wilson at Harvard University, at Martin Stute at Columbia University were assembled.

This in-class activity was divided into 2 phases. The first phase was comprised of specialized group orientations for which students gathered into 3 mediumsized groups (each with $\sim 15$ students) to learn about their specialized roles as a geologist, a water consultant, or a Bangladeshi villager. Members of the geologist group were provided with a packet of information on the distribution and known mobilization pathways of arsenic. Members of the water consultant group were given a packet of information that described an array of water treatment strategies for arsenic removal from groundwater and long-term collection of surface water. Members of the villager group were given a packet of information about the local water customs and practices. An activity facilitator worked with each of these mediumsized groups to discuss the information presented in packets, provide a crash course in simulating "expert" thinking associated with their specialized role, inform them that they were going to responsible for educating their small group members about their specialty area, and encourage them to discuss questions and issues they thought might arise during the small group discussions to follow.

After $\sim 20$ minutes, the instructor initiated the second 
phase of this in-class activity, where the specialized orientation groups disbanded and the students assembled into 3-person working groups that were comprised of a geologist, water consultant, and villager. "Experts" in each group taught each other the key concepts they learned during their specialized group orientations. The groups then explored the causes of arsenic contamination in the groundwater, and they critically evaluated the pros and cons of several proposed strategies for obtaining safe water. As they did this, each student completed the worksheet for the in-class activity.

The follow-up homework to this activity required that the students individually review the information available in all of their packets and revisit the discussions recorded on their worksheets. Each student was first asked to evaluate the relative importance of comprehensively measuring the arsenic concentration in tube-wells, informing the population of the dangers of arsenic contaminated groundwater, and finding new sources of drinking water. Then, each student assessed some of the pros and cons of well-switching, deep-well insertion, inhouse arsenic filtration, building new community wells, or relying upon rainwater harvesting, as discussed in their small groups. Finally, each student articulated their preferred approach for obtaining safe water in the shortand long-term.

\section{ASSESSMENT}

To evaluate to what extent the goals of (1) improving student attitudes towards science and learning science (i.e. develop students' sense of comfort and empowerment to learn, make sense of, and use science in their day-to-day lives) and (2) improving students' content knowledge and conceptual understanding were achieved, we used 5 different assessments: (i) pre-instruction entrance questionnaire, (ii) pre- and post-instruction attitudinal survey, (iii) pre- and post-instruction course test, (iv) postinstruction exit questionnaire, and (v) post-instruction exit interviews. These assessments were informal in the sense that they had not been subjected to rigorous validation and reliability tests during their development. They were administered by the Science Teaching Fellow and the identities of students were anonymous to the instructor. Only the pre-instruction entrance questionnaire was completely anonymous to both the Science Teaching Fellow and the instructor. Student participation in these assessments was voluntary.

\section{General Pre-instruction Entrance Questionnaire}

The pre-instruction entrance questionnaire was a paper-and-pencil survey. No incentives were provided for completing the questionnaire. Students completed it in class during the first class meeting. The questions were developed by the instructor and Science Teaching Fellow. It consisted of 14 questions, only 2 of which will be discussed:

(1) Why are you taking this class?

(2) Do you prefer to work on class material alone or with others?

\section{Pre- and post-instruction Attitudinal Survey}

The pre- and post-instruction attitudinal survey was administered online. As an incentive for completing each survey, the instructor offered students 6 bonus clicker points for their participation. Students completed the preand post-instruction attitudinal surveys during the first 2 weeks and the last 2 weeks of the semester, respectively. The survey consisted of 38 5-level Likert items that were modified from the Colorado Learning Attitudes About Science Survey (CLASS) (Adams et al., 2006) and developed by Jennifer Stempien (Stempien, unpublished). Students could choose from 5-levels of responses, ranging from "strongly disagree" to "strongly agree." A list of the 38 items is provided on the SEI archive site as Supplemental Figure 2. These items were sorted into 3 broad categories dealing with (a) studying, learning, or understanding (20 items); (b) connections to everyday life (6 items); and (c) the nature of science ( 9 items). Note that question \#17 is only used as part of the quality control of survey completion.

\section{Pre- and post-instruction Course Tests}

The pre-instruction course test contained a total of 38 multiple-choice and open-ended questions, and it was paper-based. The post-instruction course test contained 25 multiple-choice questions, and it was paper-based and utilized a Scantron bubble sheet. No incentives were provided for completion of these tests, and the results of the tests did not impact the students' course grades. Students completed the pre- and post-instruction course test during the first and last week of the semester, respectively. Between the pre- and post-instruction course tests, 14 multiple-choice questions were held in common. Only these 14 questions can be used to assess learning gains (g) achieved over the semester. Learning gains (g) for each question and the class's overall performance on all 14 questions were computed using the formula:

$$
\begin{aligned}
& g=(\text { post } \% \text { correct }- \text { pre } \% \text { correct }) /(100-\text { pre } \% \\
& \text { correct) (Hake, 1997) }
\end{aligned}
$$

Of the 14 questions, 3 questions were derived or modified from the Geoscience Concept Inventory (GCI) (Libarkin and Anderson, 2007), and the other questions were written by the instructor and teaching fellow. Each question had 3-5 answer options from which students could choose. A list of the 14 questions asked is provided on the SEI archive site as Supplemental Figure 3. For a copy of the associated answer choices, please contact the corresponding author.

\section{General Post-instruction Exit Questionnaire}

The post-instruction exit questionnaire was administered online. The instructor offered students 6 bonus clicker points for their participation. Students completed the questionnaire during the last 2 weeks of the semester. The questionnaire consisted of Likert-scale and open-ended questions. The questions were derived and or modified from a similar questionnaire administered in a Historical Geology course taught in the same department (Stempien, unpublished). Answers to open-ended 
questions were categorized with other similar student responses. A total of 17 questions were asked; however, questions relating to lecture, clicker questions, office hours, etc. are not discussed here and only 6 questions particularly relevant to this study will be discussed:

(1) How helpful were the following to your learning? (The question included a list of different course components including in-class activities and homework. Likert-scale question: from "not very helpful at all" to "very helpful.")

(2) Why were the in-class activities helpful or not helpful? (Likert-scale question: from "not helpful at all" to "very helpful.")

(3) How challenging were the in-class activities? (Likert-scale question: from "very easy" to "very challenging.")

(4) How many in-class activities would you recommend having in a semester? (Open-ended question.)

(5) What is your opinion about the homework given in this class? (Open-ended question.)

(6) Think about one geoscience idea you feel you really understand and learned from this course. Describe when, in all the different types of activities (lecture, homework, reading, lab, discussion, exam, etc...) centered around that topic, it really clicked. (Open-ended question.)

\section{Post-instruction Exit Interviews}

The post-instruction exit interviews were conducted in person by the teaching fellow during the last 4 weeks of the semester. Students were paid at a rate of $\$ 15 / \mathrm{hr}$ for their interview time. These were structured interviews to solicit student views about various aspects of the course (e.g., textbook, course website, lecture notes, etc.). Questions followed the same general format. For example:

(1) What did you think about the homework?

(2) What did you like or not like about the homework?

(3) Could you elaborate on [something the student said in response to a scripted question]?

Broad questions were asked as a means of probing what was most important to the student. Student responses to the questions were categorized. These categories were created a posteriori based on the emergent responses; therefore, not all students made comments that addressed the broad categories. The interviews were audio taped and transcribed. The responses to questions dealing with lecture, in-class activities, and homework will be discussed.

\section{Class Observations}

Class observations were made during the in-class activities by the instructor, teaching assistant, and teaching fellow. These observations were made while circulating around the room, visiting each small group, and facilitating small group discussions. As primarily participants in the implementation and facilitation of the in-class activities, the role of observer was by necessity secondary in nature and no formal rubric was rigorously applied to score the quality of the small group interactions and/or assess the prevalence of various misconceptions and learning difficulties evidenced during the course of in -class activities. Nevertheless, these observations were critical from an instructional standpoint. They were discussed by the instructor, teaching assistant, and teaching fellow both during an in-class activity in order to respond to and anticipate similar behaviors and questions from other groups of students and after the in-class activity as a means to reflect on their perceived effectiveness of the current activity and to inform their design of the next in-class activity.

\section{RESULTS \\ Student Responses: \\ Pre-Instruction Entrance Questionnaire}

The pre-instruction entrance questionnaire was completed by 39 students. All 39 students provided 1-2 reasons for taking the class. Table 1 lists the reasons students had for taking the course and how commonly held each reason was among them. One student's response accurately captures the majority's reasons for taking the class:

"I am taking it primarily as a [natural science] credit requirement, but this [the underline for emphasis was included in the student's written response] class specifically because the topic sounded interesting and one that might provide information useful outside of the classroom."

Of the 35 students that answered this question, they responded in almost equal numbers regarding their preference for working on class material alone or with others: 13 preferred working with others, 12 preferred working alone, and 9 said they liked working under both conditions or didn't have a strong preference either way. Students who said they preferred working together offered similar reasons for this preference, including:

\section{"I learn better when discussing things."}

TABLE 1.

\begin{tabular}{|l|l|}
\hline REASON FOR TAKING COURSE & $\begin{array}{l}\text { NUMBER OF } \\
\text { STUDENTS }\end{array}$ \\
\hline Satisfies natural science credit requirement & 24 \\
\hline $\begin{array}{l}\text { Only science class with space at time of } \\
\text { registration }\end{array}$ & 4 \\
\hline Is a geology credit & 2 \\
\hline Interesting or useful subject & 22 \\
\hline Enjoy geology & 1 \\
\hline
\end{tabular}

${ }_{1}^{1}$ Reasons students had for registering for the Environmental Geology course, as indicated on the pre-instruction entrance questionnaire. 
TABLE 2

\begin{tabular}{|l|c|c|c|c|}
\hline \multicolumn{1}{|c|}{ ITEM CATEGORY1 } & $\begin{array}{c}\text { TOTAL NO. OF } \\
\text { ITEMS }\end{array}$ & $\begin{array}{c}\text { + SHIFT } \\
\text { (NO.) }\end{array}$ & $\begin{array}{c}\text { - SHIFT } \\
\text { (NO.) }\end{array}$ & $\begin{array}{c}\text { NO SHIFT } \\
\text { (NO.) }\end{array}$ \\
\hline Studying, learning, and understanding & 19 & 9 & 7 & 3 \\
\hline Connections to everyday life & 8 & 5 & 3 & 0 \\
\hline Nature of science & 10 & 6 & 3 & 1 \\
\hline
\end{tabular}

1Summary of overall shifts associated with items from each category found on the pre- and post-instruction attitudinal surveys.

"Communication. We know more together."

"Groups help us to understand ourselves better."

Students who preferred to work alone had a broader range of reasons for their preference, including:

"Because I don't trust other people to do my work well."

"Because I don't feel pressured to do all of the work."

"It is difficult to organize and coordinate group work, especially outside of class."

"People just distract me from completing assignments."

"I learn more this way."

\section{Pre/Post Attitudinal Surveys}

Both pre- and post-instruction attitudinal surveys were completed by 22 students. Having matched pre- and post- student responses was necessary for tracking potential shifts in attitude; so, although more students completed either the pre- and post- surveys, their responses are not discussed. The group of 22 students for whom we have matched data showed positive shifts towards more expert-like attitudes in their responses to 20 items (indicated by " + " in Supplemental Figure 2 on the SEI archive site) and negative shifts towards more novicelike attitudes in their responses to 13 items (indicated by
"_" in Supplemental Figure 2 on the SEI archive site). For each item, an arbitrary cut-off of $5 \%$ or more was considered a significant shift either in a positive or negative direction. Items with $<5 \%$ changes in aggregate data between pre- and post- responses were not considered to show no shift. Positive shifts represented increases of $5-23 \%$ (depending on which item) towards more expert-like attitudes and negative shifts represented decreases of $9 \%$ to $27 \%$ (depending on which item) towards more novice-like attitudes. Table 2 summarizes the overall shifts by category. A few items showed no shifts. Nine out of the 19 items in the learning, studying, and understanding category showed positive shifts, 5 out of the 8 items in the connections in everyday life category showed positive shifts, and 6 out of 10 items in the nature of science category showed positive shifts.

\section{Pre/Post Course Tests}

Matched pre- and post-instruction course tests were submitted by 38 students. The higher response rate is because these tests were administered in class as a voluntary learning tool rather than as a voluntary online survey. As with the attitudinal survey, more students completed either one of the pre- and post-instruction tests; however, only the tests with matched data are discussed.

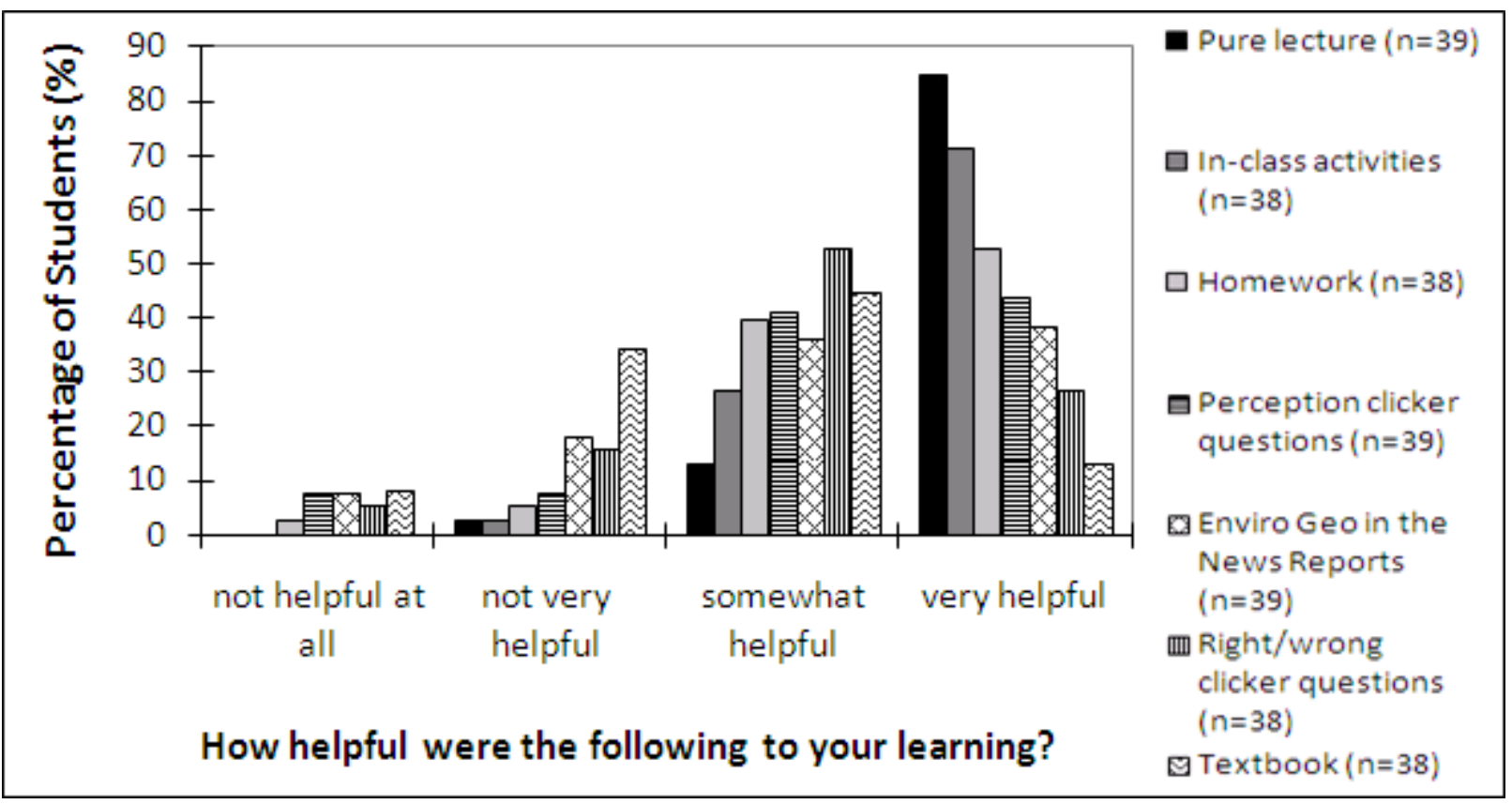

FIGURE 1. How helpful students found different aspects of th course to their learning th course material, based on responses to the post instruction exit questionnaire. 
TABLE 3.

\begin{tabular}{|l|l|l|l|l|l|l|l|l|l|l|l|l|l|l|}
\hline $\mathbf{Q}^{1}$ & $\mathbf{1}$ & $\mathbf{2}$ & $\mathbf{3}$ & $\mathbf{4}$ & $\mathbf{5}$ & $\mathbf{6}$ & $\mathbf{7}$ & $\mathbf{8}$ & $\mathbf{9}$ & $\mathbf{1 0}$ & $\mathbf{1 1}$ & $\mathbf{1 2}$ & $\mathbf{1 3}$ & $\mathbf{1 4}$ \\
\hline $\mathrm{g}$ & + & + & + & + & + & + & + & + & + & + & + & + \\
\hline
\end{tabular}

${ }^{1}$ Learning gains $(\mathrm{g})$ associated with each of the matched questions $(\mathrm{Q})$ found in the pre- and post-instruction course tests. Question numbers (\#) correspond with the questions in Supplemental Figure 3 on the SEI archive site.

Of the 14 common questions asked on the pre- and postinstruction tests 11 showed positive learning gains and 3 showed negative learning gains. The exact learning gains (g) associated with each question $(\mathrm{Q})$ are listed in Table 3. As a class, the overall pre-instruction score for these 14 questions was $31.3 \%$ and the post-instruction score was $99.8 \%$, and the class's overall learning gain $(\mathrm{g})$ was 0.99 .

This overall learning gain $(\mathrm{g})$ reflects the change from the low overall performance of the class on the preinstruction course test to its much improved overall performance on the post-instruction course test. Table 3 and Supplemental Figure 3 on the SEI archive site in combination show that the most notable ( 0.30 or higher) learning gains were related to locating the position of tectonic plates (Q1), defining a mineral (Q8), applying rock porosity and permeability to groundwater flow (Q5), and predicting surface water flow based on given river channel parameters (Q7). Persistent misconceptions were associated with explaining the cause of mineral crystal size (Q2), explaining the cause of plate tectonic movement (Q4), predicting the direction of groundwater flow in an overpumped aquifer (Q6), comparing primary and secondary waste water treatment (Q12), and predicting the morphology of a contaminant plume given information about flow rate (Q13). Based on comparisons of the pre- and post-instruction course tests' results, 5 persistent misconceptions and learning difficulties were identified. These misconceptions and learning difficulties as well as their prevalence at the end of the semester are summarized in Table 4.

\section{Post-Instruction Exit Questionnaire}

Post-instruction exit questionnaires were submitted by 39 students; however, not every student answered every question. Thirty-seven to 39 students answered each question. Figure 1 shows that the aspects of the course that the students found most helpful to their learning were lecture $(85 \%)$, in-class activities $(71 \%)$, and homework (53\%). When asked specifically about the degree to which in-class activities were helpful to their learning, all students who submitted the survey said that the in-class activities helped to varying degrees, with $92 \%$ saying that the in-class activities provided "much help" and "very much help" (Figure 2).

Based on sorted responses to an open-ended question on the questionnaire, the most popular reason $(31 \%)$ why students found them helpful was the collaborative learning [students' words] that occurred during the activities. Another $11 \%$ of students reported that the in-class activities helped them to learn the material [students' words], with no mention of collaborative interactions. Thus, $42 \%$ of respondents reported that the in-class activities were helpful because they in one way or another facilitated their learning of the course material.

Based on a comparison of student responses to the likert-scale question whose results are illustrated in Figure 2 and the above mentioned open-ended question, the most popular reason for the helpfulness of the in-class activities to students who said that the exercises were of "moderate help" to "very much help" was collaborative learning [students' words]. Students said, for example, that they were able to "get different perspectives and help from

TABLE 4.

\begin{tabular}{|l|c|}
\hline MOST PERSISTENT MISCONCEPTIONS AND LEARNING DIFFICULTIES1,2 & $\begin{array}{l}\text { RESPONDENTS AT END } \\
\text { OF SEMESTER (\%), N=38 }\end{array}$ \\
\hline $\begin{array}{l}\text { Mineral crystal size is due to the time spent at the Earth's surface rather that the time it took to } \\
\text { form. }\end{array}$ & 26 \\
\hline $\begin{array}{l}\text { Magnetism from the Earth's spinning core is responsible for the movement of tectonic plates. } \\
\text { Groundwater flow can not go against the prevailing direction of flow governed by topography }\end{array}$ & 26 \\
\hline $\begin{array}{l}\text { Pathogen removal is common to both primary and secondary waste water treatment. } \\
\text { Applying first principles of dispersion, diffusion, and flow rates to predict contaminant plume } \\
\text { morphology is difficult* }\end{array}$ & 37 \\
\hline
\end{tabular}

${ }^{1}$ Based on findings from comparisons of the pre- and post-instruction course tests.

${ }^{2}$ Here, "difficult" means that students were not able to successfully make correct predictions on the pre- and post-instruction course tests. 
their peers." For the few students who said that the inclass activities were of "little help" $(0.5 \%)$ to "moderate help" $(23 \%)$, the most popular reason given for the lack of helpfulness was that the activities were not challenging enough [students' words] for them.

Nevertheless, based on student responses to another Likert-scale question on the questionnaire, most students $(85 \%)$ did think that the in-class activities were "moderately challenging" to "very challenging," whereas only a few of them (15\%) thought that the in-class activities were "easy" or "very easy." It is worth noting that some students who found the activities too easy nevertheless found them helpful. For example, one student wrote an additional comment, "Some aspects of the [in-class activities] seemed elementary, but they helped me understand the material." Students were also asked what they recommended as the total number of in-class activities in a semester. Thirty-nine percent of the students recommended continuing to have a total of 5 in-class activities/semester, which was significantly more popular than any of the other suggestions, which ranged from 115.

When asked about their opinion about the homework, students' responses varied within a range of 7 broad categories. These categories and their prevalence are shown in Table 5. Student responses that fell in the third through fifth categories could be further narrowed into one overarching opinion - the homework was helpful in facilitating learning in various ways. This overarching opinion was held by $81 \%$ of the respondents.

The final question on the questionnaire solicited students' self-assessments of what topics they learned well during this course and what aspects of the courses they attributed that learning to. Twenty-five students answered this open-ended question and provided one topic that they thought they understood well. Of these 25 responses, $64 \%$ related to ground water $(48 \%)$ and water contamination $(16 \%) ; 20 \%$ related to the rock cycle and rock formation; and the remaining $16 \%$ reflected a mix of volcanoes, waste management, and management of natural resources. Of these 25 responses, 21 specified one or more aspect(s) of the course that helped them learn the topic. The aspect of the course that they thought most helped them learn were the in-class activities (43\%), followed by the home-work (38\%), lecture $(33 \%)$, clickers and discussion $(14 \%)$, and reading the textbook (5\%).

\section{Post-Instruction Exit Interviews}

Nine students volunteered to be interviewed, 5 males and 4 females. In describing the results of the interviews, all italicized words are reflections of the actual words that the students used, and the broad categories of student responses that emerged from the interviews are underlined. All interviewees are referred to as "he" regardless of actual sex.

It terms of the overall collaborative class-long in-class activities, the interviewees liked most of the exercises, found them helpful for doing the homework assignments, and liked inclass group exercises as a precursor to independent homework." In terms of the interviewees' self-assessment of their learning during the in-class activities, all of them said they thought the in-class activities were helpful to their learning for various reasons (particularly because of productive group dynamics) and only 1 noted that the effectiveness of the exercises on facilitating student learning depended on the quality of the group interaction, which he said was sometimes productive and sometimes not.

Activity specific comments that the interviewees had included the following. The Rock Cycle activity was helpful for understanding key concept of rock transformations, for HW and tests; too repetitive; and moving around room was difficult. The Subsurface Water activity was an effective way to illustrate concept of rock layers; hands-on and the group work was really helpful; and it wasn't clear in the instructions that they were expected to form a bowl shape. One student thought it was juvenile to play with playdough, but most interviewees said that they really liked this aspect of the exercise because it was both fun and helped in visualizing what was happening in the subsurface. Comments about the Colorado "Uranium Boom" activity included: group interactions were productive; discussed issues they saw

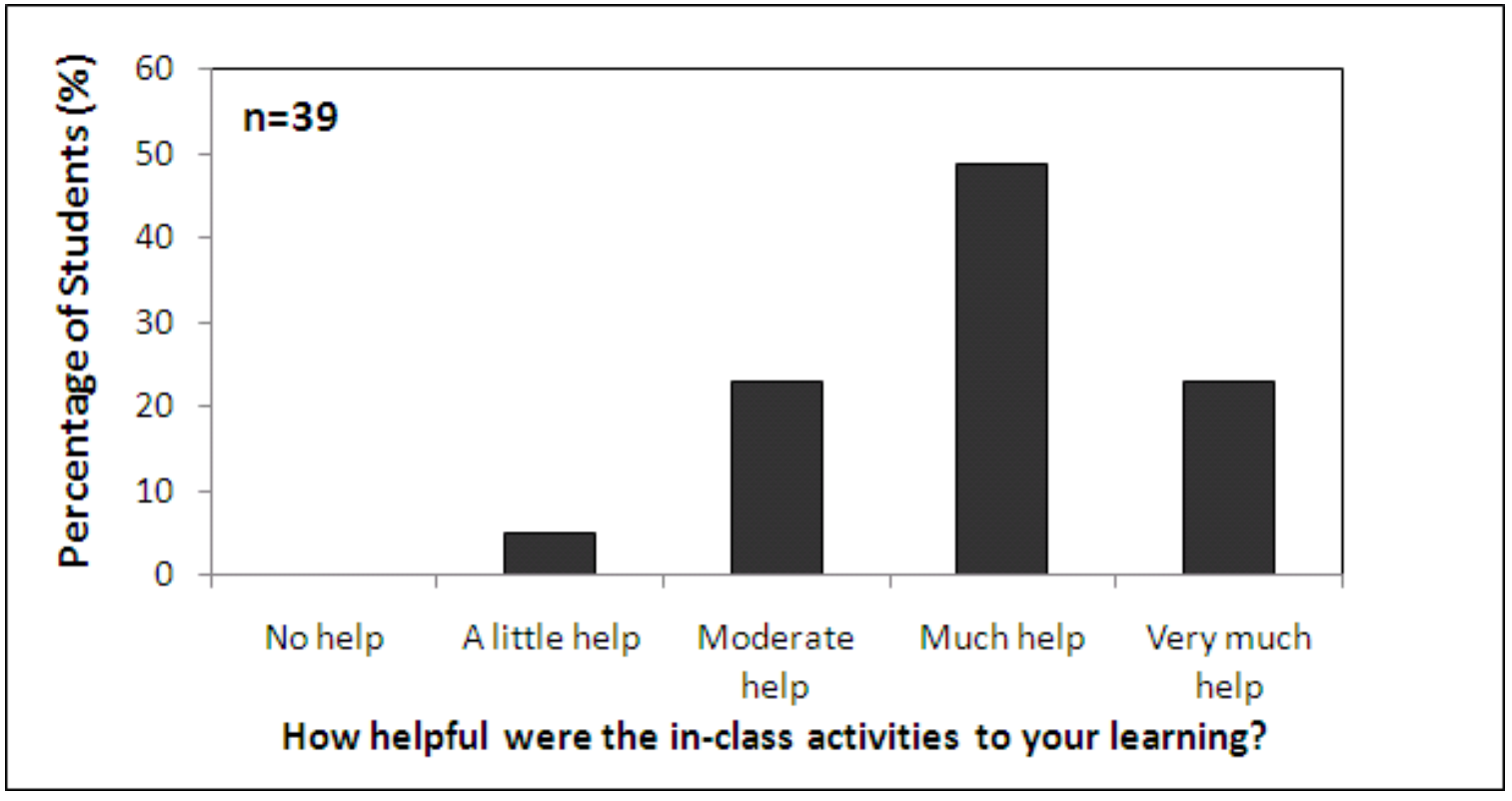

FIGURE 2. How helpful students found the inclass activities to their learning, based on responses to the postinstruction exit questionnaire. 
relevance in because it was their home state; liked real world application; would have liked questions answered in class instead of having instructor look up all the answers, which seemed like more work than it was worth to the students. The Water Quality and Drinking Water Standards activity was a challenge because some students didn't have enough prior knowledge to draw upon in the first part of the exercise; and was an opportunity to talk about stuff that hadn't thought about before; and, one student said he didn't learn anything from it. Arsenic Poisoning in Bangladesh activity - Due to the scheduling of interviews, only 1 student had participated in this final in-class activity by the time he was interviewed. He said, "The arsenic one was really interesting but there was so much coming at you and you didn't have enough time to process everything."

Suggestions made for improving the overall in-class activities included: make the exercises more involved or challenging; have more time for the exercises; make different students responsible for different aspects of an exercise; give an introductory overview before the day of the exercise; before the end of class, reconvene the class to go over the in-class exercise to make sure the different groups came away without major misconceptions before doing their individual homework assignments; and do inclass exercises on different days on different weeks (i.e. not always on Fridays). Two of the interviewees also suggested making the classes longer, from 50-minutes to 75-minutes long, to allow more time to work on and finish the in-class activities during the class period.

Regarding the overall homework, students thought that they were fine, thought-provoking, helpful for preparing for mid-terms, a chance to learn about issues relevant to our generation, and that the answer keys [were] helpful. One student also added, "I don't dread doing the homework." Homework specific comments that the students raised included: the rock cycle homework unexpectedly required creative thinking, and the flood frequency homework was a challenge and they didn't feel they were prepared with the necessary background to complete it. It is worth noting that the flood-frequency homework was one of the few homework assignments that was not coupled to an inclass activity.

\section{Class Observations \& Instructor Reflections}

For the instructor, the in-class activities provided the most tangible learning opportunities for students and repeatedly served to highlight student misconceptions regarding material covered in lectures. In the first Rock Cycle activity, it was revealed that many of the geologic processes covered in lecture prior to the activity were still not tangible to many of the students. For example, it was particularly challenging for each small group to predict whether sediments would transform into a sedimentary rock, a metamorphic rock, or magma. Discussions between students and the roving instructor, teaching assistant, and teaching fellow, revealed that students lacked a conceptual understanding of the geothermal gradient and of how temperature and potential rock transformations are closely tied to burial depth. For the Subsurface Water activity, it was revealed that students were initially determined to maintain rock layers in horizontal positions, had difficulty visualizing how rocks might dip at angles into the subsurface, and were challenged with the idea that tectonic processes can form basins. However, once they bent and cut their models, they were able to successfully visualize and analyze the

TABLE 5.

\begin{tabular}{|c|c|}
\hline CATEGORIZED STUDENT OPINIONS ABOUT THE HOMEWORK & $\begin{array}{l}\text { PREVALENCE OF OPINION (\%), } \\
\qquad \mathbf{N}=37\end{array}$ \\
\hline (1) Too easy: Not challenging enough, too easy; mundane, repetitive ${ }^{2}$ & 5 \\
\hline (2) Too hard: Difficult; somewhat confusing & 2 \\
\hline $\begin{array}{l}\text { (3) Challenging enough, interesting, and/or helped learning: Interesting/challenging/ } \\
\text { hard at times BUT interesting/good way to expand on topics AND/OR helped student learn/ } \\
\text { understand material; helpful/useful in learning/understanding material; reinforced lecture }\end{array}$ & 49 \\
\hline $\begin{array}{l}\text { (4) Opportunity to think about, apply, and/or synthesize: Opportunity to think about and/ } \\
\text { or apply material learned in class; think independently; perception questions in HW were help- } \\
\text { ful; helped synthesize material and give broader perspective }\end{array}$ & 27 \\
\hline $\begin{array}{l}\text { (5) Opportunity to gauge personal level of understanding: Demonstrated understanding; } \\
\text { way to know what student knows and doesn't know }\end{array}$ & 5 \\
\hline $\begin{array}{l}\text { (6) Connected to the real world outside of the classroom: } \\
\text { Made concepts real; helpful because showed real world examples }\end{array}$ & 2 \\
\hline (7) Contributed to course grade: Another way of getting points other than exams & 10 \\
\hline
\end{tabular}

-1Prevalence of 8 categories of student opinions about the homework, based on student responses to the post-instruction exit questionnaire.

-2Words in italics are samples of students' actual responses. 
three-dimensional basin structure and begin to assess the aquifer properties.

The third exercise, the Colorado Uranium Boom activity, marked a major transition in students' confidence in their ability to learn the course material and a greater sense of empowerment in applying what they learned previously in the class to form science-based opinions and decisions about real and current environmental issues. Although the NPR radio interview was about a year old, articles on this same issue were appearing in the local newspapers daily. Most students were attuned to these events in the daily news, and they were surprisingly eager to dissect the information presented in this in-class activity by NPR and the mining company. The students were excited to find that, when they teamed up in their small groups, they had the nascent tools necessary to collaboratively explore new mining practices, evaluate possible environmental threats, and suggest informed recommendations for community action in response to a proposal to locally develop and implement new mining technologies.

In the Water Quality and Drinking Water Standards activity, students individually articulated a distrust of or fear about the quality of drinking water; however, they were more often than not hard-pressed to explain exactly what in their drinking water might harm them. The extent of students' inability to identify and discuss the variety of possible contaminants found in water, even in layman's terms, was unexpected. The collaborative activity provided students the security of a small group environment and more personal interactions (with each other and the instructor, teaching assistant, and teaching fellow) to collectively recognize the limitations of their knowledge base, to together struggle to acquire and integrate new knowledge into their existing mental models, and to re-examine their worries about drinking water quality in light of their new knowledge of contaminants and water quality standards.

The final Arsenic in Bangladesh activity was complex to prepare and enact, but it did successfully elicit vigorous collaborative efforts to address an elaborate problem that has no currently accepted solution. By learning together to assess the scientific challenges (e.g., determining the source, distribution, and concentration of arsenic), the engineering challenges (e.g., what filtration or water collection systems will work in a robust, cheap, and easily distributed fashion), and cultural barriers (e.g., collaboration between foreign experts and local residents, dissemination of information, and individual versus community access to water). This capstone activity seemed to instill the greatest sense of confidence among the students. This emergent sense of empowerment is likely tied to the ability they demonstrated to themselves, their group, and the instructor to cogently apply most of what they learned during the semester to a serious problem in order to answer the questions posed through this activity. In the instructor's estimation, the final homework associated with this activity was the most conceptual and required students to explicitly provide individual in-depth analysis of several issues, yet students achieved their highest scores on this assignment (class average $>96 \%$ ).

\section{DISCUSSION \\ Sample Size}

Of the 52 students in this class, we had variable levels of participation with the assessments we used. To recap, 39 students completed the pre-instruction entrance questionnaire, 22 students completed BOTH the pre- and post-instruction attitudinal survey, 38 completed BOTH the pre- and post-instruction course test, 39 participated in the post-instruction exit questionnaire, and 9 participated in 1-hr interviews. Although incentives such as bonus clicker questions were sometimes offered, participation was strictly voluntary. The fact that participation was voluntary explains the fact that the response rate was not $100 \%$. The response rates ranged between $42-75 \%$ for the questionnaires, surveys, and tests. Interviews had a response rate of $17 \%$. Babbie (1986) suggests that a $50 \%$ response rate for a questionnaire is adequate, $60 \%$ is good, and $70 \%$ is very good. Thus, our response rates ranged from less than adequate to very good, depending on which assessment it was. In the future, we could improve the response rates of assessments by making them a homework assignment that counts towards their grade and/or integrating several survey questions into their course exams. Although we did not have 100\% response rates, the respondent populations were representative of the larger class population. Furthermore, the data triangulation possible with the different kinds of information collected provided valuable insights into understanding the students' attitudes about science and learning science, about their content knowledge and conceptual understanding, and how the coupled collaborative in-class activities and individual follow-up homework could have contributed to their development over the semester.

\section{Intrinsic Interest \& Perceived Overall Value}

The findings of our pre-instruction entrance questionnaire indicate that the primary reasons why the students enrolled in this course were (a) to satisfy a natural science requirement and (b) because they thought that the subject would be interesting or useful. The fact that they were taking it to satisfy a natural science requirement was not surprising given that the course is an introductory-level course in the Colorado Core Curriculum. However, the fact that the students took the class because they thought it would be interesting or useful was not a guarantee and it was certainly what the instructor had hoped for. This was undoubtedly a real asset in terms of engaging students through the coupled collaborative in-class activities and individual follow-up homework because they already had an intrinsic interest and underlying motivation to learn the subject.

In student interviews, respondents found the in-class activities and homework very helpful for their learning, saying that they liked working in groups because they could learn from each other, that they could prepare for doing the homework alone while they had peer support in class, and that they liked working on the homework independently because it gave them time to think and work at their own speed. In the post-instruction 
questionnaire (n=37-39), the majority found the homework, in-class activities, and lecture to be somewhat to very helpful. In terms of the numbers of the students that found these different components very helpful, from most to least: lecture $>$ in-class activities $>$ homework.

Although this might be perceived as a concern by some of our readers, we can provide several possible reasons for why more students thought that lecture was very helpful as compared to the other two aspects of the course. (1) A combination of findings from the attitudinal survey and the interviews suggests that students believed that the instructor was approachable and explained things well (interviews) and that they could not learn environmental science if the teacher didn't explain the material well (attitudinal survey, item 7). (2) The mid-term and final exam questions were worth $50 \%$ of their grade, and these exams covered lecture material rather than the in-class activities, which were assessed by the homework. (3) To complete the in-class activities and homework, there was always a built-in relationship to the lecture materials, which may have highlighted the helpfulness of the lectures to the students. Perhaps what is most important is that many students found lecture and in-class activities very helpful for their learning and not a single student recommended eliminating the in-class activities from future iterations of the course such that the course would become entirely lecture-based.

\section{Perceived Learning, Measured Learning, \& Perceived Specific Value}

The post-instruction exit questionnaire showed that $64 \%$ of the respondents thought that they understood the topics of groundwater and/or water contamination really well; $20 \%$ thought they understood the topics of the rock cycle and rock formation really well. The remaining 16\% thought that they understood a variety of different topics very well, including volcanoes, waste management, and management of natural resources.

According to the results of the matched preinstruction and post-instruction course tests, students showed remarkable learning gains for 11 out of the 14 questions. These questions dealt largely with groundwater, groundwater contamination, and minerals and rocks. Thus, the students' perception of their own learning is supported by external measures of their learning. This is perhaps surprising because the educational literature has well documented students' general overestimation of what they think they know and what they think they can do (e.g. Boud and Falchikov, 2004). It is, however, also very encouraging from an instructional standpoint because the students appear to be learning what they think they are learning. Furthermore, these findings suggest that we were successful in achieving one of our overarching student learning outcomes - improve students' content knowledge and conceptual understanding. Here, however, it is necessary to remember that the coupled collaborative in-class activities and individual follow-up homework were a major part of the course but not the only part where student learning could occur. The improvements in their content knowledge and conceptual gains are also influenced by other components of the course, such as lecture.

Although the learning gains were remarkable, there were also several persistent misconceptions and learning difficulties. Five in particular emerged from comparisons of the results of the pre- and post-instruction course tests (Table 4). Although we did not formally investigate the reasons for their persistence, the reasons are likely to be varied and concept-dependent. For example, the sources of the apparent persistence may be due to deeply rooted and salient mental models (e.g. (i) the perceived correlation between crystal size and time spent at the Earth's surface and (ii) the perceived connection between Earth's magnetic field, spinning core, and tectonic movement), the need for more time spent on tasks to more deeply learn challenging concepts (e.g. the relationships between groundwater flow and topography), and failure to memorize important aspects of different processes and first principles (e.g. regarding primary and secondary water treatment, dispersion, and diffusion).

In their responses to the post-instruction exit questionnaire, many students explained what aspects of the course they felt helped them understand the topic(s) that they understood very well. According to these results, the component of the course that most helped students learn these self-identified topics were the in-class activities $(43 \%)$, followed by the homework (38\%), lecture $(33 \%)$, and other components (19\%). Thus, when asked what components of the course helped them to learn the topics that they felt they most well understood, students had a different overall response than they did compared to when they were asked broadly what helped them to learn the course material. In terms of the numbers of the students that attributed different components of the course to their learning of specific topic(s) they thought they learned well, from most to least: in-class activities > homework > lecture. From an instructional standpoint, it's extremely encouraging to see that students thought that they were learning the concepts that they most deeply understood by engaging in the in-class activities and homework. This kind of feedback combined with the positive learning gains observed in the pre- and post-instruction course tests helps make the investment of time and energy needed for the design and implementation of these coupled in-class activities and homework worthwhile from an instructional standpoint.

\section{Attitudes about Science and Learning Science}

As for our other overarching student learning outcome - improve student attitudes towards science and learning science (i.e. develop students' sense of confidence and empowerment to learn, make sense of, and use science in their day-to-day lives) - the pre- and postinstruction attitudinal survey sheds some light on the shifts in their attitudes about learning science, in what ways they view science being connected to their lives, and their views about the nature of science. At the end of the semester there was a positive shift in the number of students that had more expert-like views regarding using graphs to facilitate understanding and maintaining interest even in light of a complicated diagram. They also 
had more expert-like attitudes about who can understand science and how discussion with friends can facilitate the understanding of science. There were, however, increases in more novice-like attitudes particularly regarding the relationship between memorization and learning, based on novice-shifts in 4 out of 6 of the items that dealt with memorization.

One possible reason for the apparent increase in novice-like attitudes regarding the relationship between memorization and learning may be attributed to the fact that there was quite a bit of memorization involved in the course. For example, definitions of geologic terms, constant values and rates, and first principles needed to be memorized. It is plausible that students found the amount of memorization needed to be problematic (e.g. as expressed in responses to item \#1). However, it is worth noting that without these basic foundational units of content knowledge, more sophisticated conceptual thinking and geologic problem solving would not be possible.

Although there was an increase in more novice attitudes with respect to memorization and learning, there nevertheless was a shift towards more expert-like views regarding the connection of environmental science to their lives and learning environmental science to help understand societal problems. They also had more expertlike views about the nature of science, such as viewing science not simply being a collection of disconnected facts. There were other items that showed shifts towards more expert-like and novice-like attitudes and views; however, those discussed here are most useful in our examination of changes in students' attitudes. Although we would like to say that the more expert-like shifts were somehow influenced by the collaborative in-class activities and follow-up homework, we do not have any measurable data to either support or refute it. Given the fact that the largest part of students' time actively interacting with the course material was during the in-class activities and the time they completed their follow-up homework (second only to time spent in lecture), one might suggest that they likely had an important influence on the development of their attitudes about learning science, the connections they see between science and real life, and their views about the nature of science.

\section{Instructor Reflections}

Given the time and effort invested in designing and implementing the coupled collaborative in-class activities and individual follow-up homework as well as in attempting to assess their possible impact on student learning and attitudes, we reflect upon possible changes in implementation and design. At this stage, there are 6 things that we suggest doing differently in the next iterations of implementing the coupled collaborative inclass activities and individual follow-up homework. First, the in-class activities and homework could be made more challenging by, for example, requiring more analysis and interpretation of geological and/or hydrological data. Second, provide students more time during class to work on the in-class activities by extending the class period from 50 minutes to 75 minutes by meeting fewer times per week. Third, spend more time introducing and framing the in-class activity before letting the students dive into their work. Fourth, spend time wrapping up and debriefing the in-class activity as a large class group before disbanding. Fifth, it could be beneficial to have an observer collect more detailed observations of the student interactions during the in-class activities for assessment purposes. Finally, the homework likely played a central role in achieving learning gains through the synthesis and analysis of concepts introduced in lecture and the in-class activity. Thus, an important area of future development is the careful redesign of the homework assignments to enhance their alignment with key learning goals. In addition, homework could be weighted more heavily in the overall grade for the class given its relative importance in both developing and assessing student learning.

Although there are aspects of design and implementation that were time and energy intensive, from our perspective, the in-class activities were also worthwhile especially because of the opportunities they provided for direct interactions between the facilitators and students, which were valued by both groups. Moreover, for the instructor, these classroom interactions provided the strongest feedback during the semester about student excitement, interests, ideas, learning difficulties, and misconceptions that did not surface during the lectures. We are, therefore, in agreement with the student recommendation of continuing to implement 5 in-class activities per semester.

\section{CONCLUSION}

In designing a new introductory-level Environmental Geology course for primarily non-science majors, we used a constructivist approach to teaching and learning and "backward design" to articulate learning goals, which then helped to inform our design of coupled collaborative in-class activities and individual follow-up homework. The in-class activities replaced lecture during 5 different class meetings. The activities were collaborative in nature, and small groups of students worked together to answer questions and solve problems. These in-class activities were followed up with homework assignments that students completed independently. The homework assignments were designed so that they built upon what was learned during the in-class activity, and questions often asked students to synthesize that information. The overarching student learning outcomes that drove the design of the coupled collaborative in-class activities and individual follow-up homework were (1) improve student attitudes towards science and learning science (i.e. develop students' sense of confidence and empowerment to learn, make sense of, and use science in their day-today lives) and (2) improve students' content knowledge and conceptual understanding. To assess the extent to which these outcomes were achieved we utilized 6 different kinds of assessments. These included a preinstruction entrance questionnaire, pre- and postinstruction attitudinal surveys, pre- and post-instruction course tests, a post-instruction exit questionnaire, postinstruction student interviews, and daily classroom observations. Our findings indicate that these coupled 
activities were perceived as being very helpful by the students and suggest that they helped to improve student learning gains and attitudes about learning environmental science.

\section{Acknowledgments}

Funding for course development was provided by the Geological Sciences Department's Science Education Initiative at the University of Colorado at Boulder. We thank Lisa Mayhew for her assistance in developing and assisting in the in-class exercises, and thank David Budd, Stephen Mojzsis, Wendy Adams, and Andrea Bair for their constructive comments.

\section{REFERENCES}

Adams, W.K, Perkins K. K., Podolefsky, N.S., Dubson, M., Finkelstein, N.D., and Wieman, C.E., 2006, New instrument for measuring student beliefs about physics and learning physics: The Colorado Learning Attitudes about Science Survey: Physics Education Research, vol. 2, p. 1-14.

Babbie, E., 1989, The Practice of Social Research: Belmont, California: Wadsworth, $501 \mathrm{p}$.

Beichner, R.J. and Saul, J.M., 2003, Introduction to the SCALE-UP (Student-Centered Activities for Large Enrollment Undergraduate Programs) Project in Proceedings, International School of Physics, Varenna, Italy, p. 1-17.

Bjork, R.A., 1994, Memory and Metamemory Considerations in the Training of Human Beings, in Metcalfe J. and Shimamura A. eds., Metacognition: Knowing about Knowing, Cambridge, MA, MIT Press, p. 185-205.

Boud, D. and Falchikov, N., 2004, Quantitative studies of student self-assessment in higher education: A critical analysis of findings: Higher Education, v. 18, p. 529-549.

National Research Council, Bransford, J.D., Brown, A.L., and Cocking, R.R., eds, 2000, How People Learn: Brain,Mind, Experience, and School: Washington DC, National Academy Press, $374 \mathrm{p}$.

British Geological Survey, 2008, Arsenic contamination of groundwater, http://www.bgs.ac.uk/arsenic/ (16 October 2008)

Crouch, C.H., and Mazur, E., 2001, Peer instruction: Ten years of experience and results: American Journal of Physics, v. 69, p. $970-977$.

Dewey, J., 1916, Democracy and Education: An Introduction to the Philosophy of Education: New York, MacMillan The Free Press, $455 \mathrm{p}$.

Duncan, D., 2005, Clickers in the Classroom: New York, Pearson, $72 \mathrm{p}$.

Fagen, A.P., Crouch, C., and Mazur, E., 2002, Peer instruction: Results from a range of Classrooms: The Physics Teacher, v. 40, p. 206-209.

Farver, J.R. and Brabander, D.J., 2001, Magma ascent rates from mineral reaction rims and extention to teaching volcanic hazards: Journal of Geoscience Education, vol. 49, p. 140145.

Fink, L.D., 2003, Creating Significant Learning Experiences: An Integrated Approach to Designing College Courses: San Francisco, Jossey-Bass, 295 p.

Gillespie, M., 2005, Student-teacher connection: a place of possibility: Journal of Advanced Nursing, v. 52, p. 211-219.

Hake, R.R., 1997, Interactive-engagement versus traditional methods: A six-thousand-student survey of mechanics test data for introductory physics courses: American Journal of Physics, v. 66 (1), p. 64-74.

Handelsman, J., Miller, S., and Pfund, C., 2007, Scientific Teaching: New York, W.H. Freeman and Company, 184 p.
Heller, P., Keith, R., and Anderson, S., 1992, Teaching problem solving through cooperative grouping. Part 1: Group versus individual problem solving: American Journal of Physics, v. 60 (7), p. 627-636.

Kloss, R.J., 1994, A nudge is best: Helping students through the Perry scheme of intellectual development: College Teaching, v. 42 , p. 151-58.

Lev, S.M., 2004, A problem-based learning exercise for environmental geology: Journal of Geoscience Education, vol. 52 (2), p. 128-132.

Libarkin, J.C. and Anderson, S.W., 2007, Development of the Geoscience Concept Inventory, in Proceedings, National STEM Assessment Conference, October 19-21, 2006, Washington D.C., p. 148-158.

Liu, L., Philpotts, A.R., and Gray, N.H., Service-learning practice in upper division geosciences courses: Journal of Geological Sciences, vol. 52, p. 172-177.

MacGeorge, E.L., Homan, S.R., and Dunning, J.B.,2008, Student evaluation of audience response technology in large lecture classes: Educational Technology Research and Development, vol. 56, p. 125-145.

Mayer, R.E., 1998, Learning and Instruction, New Jersey, Merrill Prentice Hall, 516 p.

Mayhew, L., and Bair, A., 2007, Actively engaging students in conceptual learning: implementing "concept challenge" home-works in large introductory geology courses [abstract]: Geological Society of America Abstracts with Programs, v. 39, p. 552.

Mazur, E., 1997, Peer Instruction: New Jersey, Prentice Hill, 253 p.

Michael, J., 2006, Where's the evidence that active learning works?: The American Physiological Society, vol. 30, 159167.

Moog, R.S., and Farell, J.J., 2006, Chemistry: A Guided Inquiry: New Jersey, John Wiley \& Sons, Inc., 368 p.

Musumeci, D., 1996, Teacher-learner negotiation in contentbased instruction: Communication at cross-purposes?: Applied Linguistics, vol. 17 (3), p. 286-325.

Premkumar, K., and Coupal, C., 2008, Rules of engagement - 12 tips for successful use of "clickers" in the classroom: Medical Teacher, vol. 30 (2), p. 146-149.

Redish, E.F., 2003, Teaching Physics with the Physics Suite: New Jersey, John Wiley \& Sons, Inc., 216 p.

Robinson, G.D., 2001, How many years does it take for a mountain to wash into the sea?: Journal of Geoscience Education, vol. 49 (2), p. 135-139.

Sagendorf, K., Noyd, R.K., and Morris, D.B., 2009, The learningfocused transformation of biology and physics core courses at the U.S. Air Force Academy: Journal of College Science Teaching, January/February 2009, p. 45-50.

Sambu, S. and, Wilson, R., 2008, Chronic arsenic poisoning: history, study and remediation, http:// phys4.harvard.edu/\% 7Ewilson/arsenic/references / arsenic_project_references.html (16 October 2008)

Schwartz, D. L., Lindgren, R., and Lewis, S., 2009, Constructivism in an age of non-constructivist assessments, in Tobias, S. and Duffy, T. eds., Constructivist Theory Applied to Instruction: Success of Failure?, (in press).

Science Education Initiative, 2008, Course Materials, http:// w w w.sei.ubc.ca/materials/sections.do? section $=$ overView $\&$ courseId $=215 \&$ departId=14 (02 July 2009)

Seymour, E. and Hewitt, N.M., 1997, Talking about Leaving: Why Undergraduates Leave the Sciences: Boulder, Westview, $429 \mathrm{p}$.

Soja, C.M. and Huerta, D., 2001, Debating whether dinosaurs should be "cloned" from ancient DNA to promote cooperative learning in an introductory evolution course: 
Journal of Geoscience Education, vol. 49, p. 150-157.

Stowell, J.R. and Nelson, J.M., 2007, Benefits of electronic audience response systems on student participation, learning, and emotion: Teaching of Psychology, vol. 34, p. 253-258.

Stute, M., 2009, http://www.ldeo.columbia.edu/ martins/ home/research.htm (2 July 2009).

Umbach, P.D. and Wawrzynski, M.R., Faculty do matter: The role of college faculty in student learning and engagement: Research in Higher Education, vol. 46, p. 153-184.

U.S. Environmental Protection Agency, 2008, http:// www.epa.gov/ogwdw/contaminants/index.html (16 October 2008)

Warner, R., 2007, Uranium mining planned in Weld County, h t t p : / / w w w. kcf r.org / i n d ex.ph p ? option=com_content\&task=view\&id $=94 \&$ Itemid=255 $\quad(16$ October 2008).

Wiggins, G. and McTighe, J., 2005, Understanding by Design: Alexandria, Virginia, Association for Supervision and Curriculum Development, $370 \mathrm{p}$.

Wilson, R., 2009, http://phys4.harvard.edu/ wilson/arsenic/ references/arsenic_project_references.html (2 July 2009).

Yair, G., 2008, Can we administer the scholarship of teaching? Lessons from outstanding professors in higher education: Higher Education, vol. 55 (4), p. 447-459.

Yuretich, R.F., Khan, S.A., Leckie, R.M., and Clement, J.J., 2001, Active-learning methods to improve student performance and scientific interest in a large introductory oceanography course: Journal of Geoscience Education, vol. 49, p. 111-119. 